\title{
Relato de experiência: \\ Descobrindo a Iniciação Científica
}

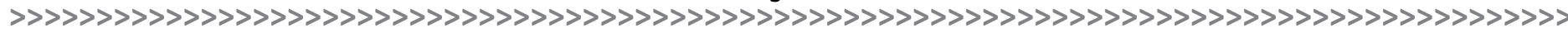

Magnólia Tebaldi*

\section{Resumo:}

Este artigo descreve a trajetória de pesquisadora de uma estudante do 9 o ano do Ensino Fundamental. A estudante conta sobre sua vida escolar sem acesso à Iniciação Científica, e as mudanças que aconteceram quando ela ingressou no Colégio de Aplicação da UFRGS, no 8o ano, com Iniciação Científica no currículo regular. Além disso, ela relata sua experiência como bolsista de Iniciação Científica, e reflete sobre os diferentes modos de fazer Ciência que vem conhecendo.

\section{Palavras-chave:}

Iniciação Científica. Ensino Básico. Colégio de Aplicação da UFRGS.

\begin{abstract}
:
This paper depicts the journey of a $9^{\text {th }}$ grade student as a researcher. The student discusses her school life and her lack of access to the Scientific Iniciation, and the changes that followed when she enrolled in Colégio de Aplicação UFRGS, in the $8^{\text {th }}$ grade, where the Scientific Iniciation is part of the regular curriculum. In addition, she describes her expirience as a Scientific Iniciation schorlarship holder, and reflects on the different ways of doing science she has been learning.
\end{abstract}

\section{Keywords:}

Scientific Iniciation. Elementary school. Colégio de Aplicação UFRGS.

\section{Introdução: Quem sou eu e de onde venho}

Fui sorteada para estudar no CAp em 2018, no $8^{\circ}$ ano. Anteriormente à minha entrada no Colégio de Aplicação, já havia passado por 3 escolas: duas particulares e uma estadual (na qual permaneci por 4 anos).

Eu não me lembro muito da minha primeira escola, que era particular, pois, saí de lá no $3^{\circ}$ ano, mas não existia a Iniciação Científica.

Depois disso, fui para um colégio estadual, e lá era muito diferente: havia mais liberdade para todas as matérias e não havia uma "cobrança" dos professores para a resolução de tarefas de casa, estudo externo, etc. Nem preciso dizer que não havia IC.

O meu terceiro colégio, diferentemente dos outros, não era em Porto Alegre. Era uma escola particular que ficava em Morungava (Gravataí), e eu estudei nele por três meses, enquanto morava lá com a minha avó. Lá, assim como nas escolas anteriores, não havia IC, mas havia a tal cobrança inexistente na escola estadual.

* $>$ Estudante dos anos finais do Ensino Fundamental do Colégio de Aplicação da UFRGS - Equipe PIXEL. Bolsista de IC Júnior. E-mail: magnoliatebaldi@gmail.com. Orientadora do trabalho: Profa Dra Vivian Ignes Albertoni. 
Eu nunca havia ouvido falar em Iniciação Científica antes de entrar no CAp, e o objetivo deste texto é relatar as diferentes experiências com Iniciação Científica que venho tendo nesta escola desde então.

\section{Parte 1: A IC 80s}

Quando cheguei no CAp, as aulas de IC eram com as turmas inteiras, e a minha era a 81. Logo entendi o que os professores queriam que fosse a Iniciação Científica: os professores queriam que a IC fosse em quatro períodos por semana, nos quais os alunos pesquisassem assuntos que os interessassem. Eu não sabia na época, mas eles queriam que a gente usasse algum método que fosse científico nas nossas pesquisas. Mais tarde, quando iniciei minhas pesquisas da bolsa IC Junior, entendi o que era o método científico tradicional e descobri o uso dele nas nossas pesquisas: é uma forma de pesquisa onde se criam novos conteúdos e se fazem testes para comprovar o que foi pesquisado.

Mais ou menos em abril, quando escolhemos a Língua Estrangeira que a gente iria fazer nos dois anos de Pixel (80 e 90), nos separaram e deixamos de ter aula com a turma inteira para ter com esses grupos menores de aproximadamente 15 pessoas. Eu fazia parte do grupo de Alemão, que era a língua que eu havia escolhido. Quando separaram pelas línguas, compreendi quais itens deveriam existir em uma pesquisa. Eu estava esperando por esse momento, pois ainda me sentia levemente confusa em como começar a pesquisar, e sinto que aquilo me iniciou no meu projeto. Portanto, compreendi os itens que eram necessários na pesquisa, como tema, assunto, pergunta de pesquisa, metodologia, como saber diferenciar o "tema da pesquisa" de "assunto", etc. Isso serviu para que eu pudesse aprofundar a minha pesquisa e não escolher um tema que fosse muito amplo.

Nossa pesquisa deveria toda ter sido ao redor do conceito Identidade, que é o conceito do $8^{\circ}$ ano; porém, no meio da nossa pesquisa, esse tema já não era mais lembrado com frequência, pois sabíamos discernir o que tinha a ver com isso ou não. $\mathrm{Na}$ época achei estranho, pois não lembrávamos disso na hora da pesquisa nem da apresentação, mas hoje consigo ver a relação criada por mim com a ajuda dos meus professores para com esse tema (Identidade).

O meu assunto de pesquisa da primeira vez foi "A influência de personagens femininas em séries de televisão". No nosso grupo havia três professores - dois que estavam ali sempre e um que ia uma vez por semana. Quando ele estava presente, havia uma orientação mais guiada dos três professores, podíamos tirar dúvidas e ficava mais fácil criar novos conteúdos. Porém, quando ele não estava presente, optava-se por uma estratégia mais livre, na qual o método de pesquisa era mais autônomo. Eu não achei que esse estilo mais livre auxiliou muito nosso grupo, pois acabávamos muitas vezes não dando continuidade ou resolução para o nosso trabalho. Portanto, essa foi a minha primeira experiência com a Iniciação Científica.

O segundo semestre foi mais delicado para o nosso grupo, pois, se no primeiro semestre houve mais liberdade para escolhermos nosso tema, assunto, objetos de estudo, etc; já no segundo projeto, não tivemos liberdade em relação a isso: os professores testaram um formato em que algumas coisas nos foram predefinidas, como o tema geral e alguns objetos de estudo, e o grupo deveria se inspirar em um filme sobre Mozart. Minha percepção é de que dessa maneira nosso aprendizado foi menor e ficou muito mais difícil de achar a pesquisa interessante e de criar novos conteúdos. Meu assunto foi "A influência de mulheres no período clássico da música erudita europeia no século XVIII", acabou parecendo, para mim, uma reorganização de conteúdos já criados anteriormente, sem que eu criasse novos conteúdos que fariam sentido para as outras pessoas que lessem sobre o meu trabalho. 


\section{Parte 2: A bolsa}

Mais ou menos pelo mês de setembro de 2018, alguns professores começaram a divulgar bolsas de estudo da modalidade IC Júnior. Os alunos poderiam escolher uma pesquisa que os interessasse para colocar em prática e, por fim, apresentar com o seu professor orientador. Eu me interessei pela pesquisa da professora Vivian, que era sobre Iniciação Científica. Me inscrevi, passei pelo processo de seleção e aqui estou.

Logo no início, fiquei perdida nos itens que ela me explicava e nos termos que usava: ela queria que eu soubesse o que era Método Científico (termo que eu nem conhecia), queria que eu relatasse como eram minhas experiências no Pixel em sala de aula (coisa que eu nunca tinha tentado colocar por escrito ou explicar oralmente), etc. Nos encontrávamos toda segunda-feira, no primeiro período da tarde e ela me explicava como queria que funcionasse a bolsa e a minha pesquisa.

No início de outubro, fomos em uma saída de campo com outros bolsistas do colégio. Fomos na Faculdade de Odontologia e assistimos a uma palestra (em inglês) sobre ratos e experimentos de laboratório utilizando-os. Essa saída de campo foi interessante para eu entender melhor os itens que eram necessários em uma pesquisa que utilizava o Método Científico, como produzir e criar teorias, depois colocá-las em prática para testá-las, etc.

Nessa saída de campo, vimos a forma clássica do método científico já conhecido por todos, onde a pessoa faz experimentos, cria novos conteúdos, faz anotações, etc. Nas nossas reuniões anteriores havíamos pensado em maneiras alternativas de utilizar o método científico e outros métodos, como na área das artes, linguagens, etc. Além disso, nessas reuniões nas quais a gente se encontrava, debatíamos o fato de existirem esses outros métodos de fazer ciência.

\section{Parte 3: Expectativa x Realidade}

A UFRGS é muito conhecida nacionalmente pela Pesquisa (ponto mais famoso do seu tripé, que ainda tem Extensão e Ensino), que é a criação de novos conteúdos e de compartilhamento de conhecimento. Com as aulas de Pixel, meus colegas e eu podíamos fazer uso dessa parte tão famosa da Universidade. No meu grupo do Alemão, no primeiro semestre (com temas mais relacionados à nossa identidade) estávamos criando conhecimento novos, o que não aconteceu tanto no segundo semestre - o que fez com que a gente não fizesse um uso tão bom dessa parte do tripé da Universidade. Já na bolsa, apesar de não ter criado conteúdo e conhecimento, entendi os itens que seriam necessários para essa criação.

Portanto, pelas minhas vivências nas aulas de Pixel, acredito que deveríamos escolher um tema que nos interessasse, que nos fizesse ir atrás de novos conteúdos para criar conhecimento, que nos proporcionasse uma Mostra divertida e que conseguíssemos, além de apresentar nosso trabalho para os outros, assistir às apresentações, nos interessar pelo tema do colega e nos divertirmos com a troca de conhecimento e informação.

Na nossa primeira mostra, fomos visitar o grupo do Espanhol 80 e percebemos que foi um dos mais interessantes, pois após todos terem escolhido seu próprio assunto de interesse e pesquisado o semestre inteiro sobre isso, escolheram um tema geral no qual todos os alunos iriam caracterizar a sala, formar subgrupos e para a apresentação na Mostra. O tema escolhido havia sido La Casa de Papel, portanto todos os alunos tinham nomes de cidades relacionadas ao seu assunto e projeto de pesquisa, todos usavam as máscaras da série de TV, etc. Esse é um dos métodos de apresentação que me parece mais interessantes. 


\section{Parte 4: Atualidade e perspectivas}

Agora, no Pixel 90, houve mudanças. Continuo na Língua Alemã, mas logo no início escolhemos os temas baseados no que nós queríamos, e não como no semestre anterior, no qual haviam nos dado o assunto e escolhemos apenas o tema e o foco da pesquisa. $\mathrm{O}$ meu tema deste semestre é relacionado com princesas da Disney e o que as torna princesas oficiais da franquia Disney Princess, além de focar nas personagens Disney que não se encaixam nessa categoria.

Ainda que esteja satisfeita com a retomada da escolha livre de tema, desde que começou o semestre, a estratégia de trabalho é aquela livre, na qual passamos muito tempo na frente do computador para pesquisar sobre o tema e, uma vez por semana, fazer um pequeno relato aos colegas e professores para entender qual o rumo que sua pesquisa está tomando.

Depois de estudar o Método Científico na bolsa de Iniciação Científica, acho que um bom passo para começar a modificar isso e organizar melhor os tempos da IC, seria fazer os alunos (e até alguns professores) entenderem como o Método Científico pode ser utilizado na IC e quais os outros jeitos que ele ou outras formas de fazer ciência (gerar conhecimento) podem aparecer, como já citado, de modo artístico, através de estudos das linguagens, etc.

\section{Conclusão}

Neste trabalho tive a intenção de relatar a minha experiência de aproximadamente um ano e meio na Iniciação Científica do CAp, que é o colégio em que eu estudo. Eu esperava que esse relato pudesse me ajudar a entender mais o que significa a IC e suas intenções para a vida do aluno das 80 e 90, e foi exatamente essa reflexão que o texto me ensinou. Na prática, espero contribuir, agora no $9^{\circ}$ ano, com a criação de novos conteúdos e produção de conhecimento no Pixel e, se possível, na bolsa IC Junior.

\section{Referências}

ARAÚJO-JORGE, Tânia C. Relação entre ciência, arte e educação: relevância e inovação. Disponível em: http://www.bio.fiocruz.br/index.php/artigos/338-relacoes-entre-ciencia-arte-e-educacao-relevancia-e-inovacao. Acesso em: 14 out. 2018.

BRITES, Blanca. (org.). O meio como ponto zero. Porto Alegre: Editora da UFRGS, 2002.

HAAG, Carlos. A tentativa de Leonardo da Vinci de unir arte à ciência. Revista Fapesp, ed. 198, ago. 2012. Disponível em: https://jornalggn.com.br/blog/luisnassif/a-tentativa-de-leonardo-davinci-de-unir-arte-a-ciencia. Acesso em: 14 out. 2018.

Projetos de Ensino das Equipes Amora e PIXEL do Colégio de Aplicação da UFRGS. 